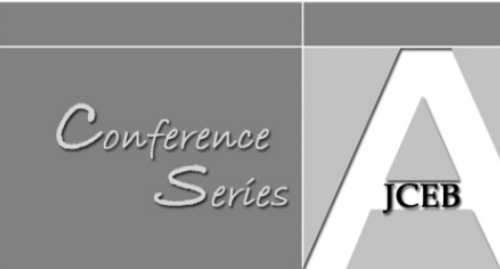

\title{
Approaches of Implementing ICT Technologies within the Construction Industry
}

M. Reza Hosseini, Nicholas Chileshe, Jian Zuo, Bassam Baroudi

(University of South Australia, Australia)

\begin{abstract}
Industry in general has seen many technological developments in recent decades. However, the construction industry has not kept pace particularly within the area of information and communication technologies (ICTs). This could be for many reasons notably including the fragmented structure of the industry. Many studies regard the construction industry's failure to keep pace with ICTs as a major problem affecting its performance. Hence, they have tried to diagnose the problem in this regard. Many drivers have seen the successful adoption of new ICTs within other industries with this trend now emerging within the construction industry. Because of the increasing awareness among practitioners of the benefits of utilising ICTs within construction, the recent decade has seen many construction projects harnessing ICTs methods and strategies in construction. This paper has an exploratory approach with the aim of reviewing the existing research publications on the subject, describing the current state of ICTs in construction industry, and introducing some successful methods. The presented discussions will provide guidelines for practitioners and policy makers in the construction industry regarding the advantages of adopting ICTs for enhancing the efficiency of the construction industry. The methods introduced could be beneficial for key construction stakeholders in developing countries by presenting the advantages gained from merging ICTs into construction projects processes based on methods previously tested in developed economies.
\end{abstract}

Keywords: ICTs, Construction Industry, Developing Country

\section{Introduction}

It is not an exaggeration to say that construction has not been one of the pioneer industries to embrace technology (Ruddock, 2006) because of being unsure about the positive effects (Andresen et al., 2000). Technological developments have been progressing fast in other industries, but construction for a long period has lagged behind other industries in terms of adoption of new technologies (Brandon et al., 2008, Peansupap, 2012, Chee, 2007). Nevertheless, exploring the main reasons behind the low implementation of ICTs in construction industry has been the objective of some papers (Ruddock, 2006, Peansupap and Derek, 2006, Davis and Songer, 2008, Love et al., 2001). On the other hand, many studies have focused on the potential for harnessing the new ICT technologies for the good of the construction industry all over the world, due to the industry's awareness of the need (Hannus et al., 2003, Adriaanse et al., 2010, Kivrak et al., 2010, Rezgui and Zarli, 2006, Gajendran and Brewer, 2012). In this regard, various studies have gone as far as to regard the gap between the construction industry and ICTs as a major problem affecting its whole performance and tried to diagnose the roots of the difficulties in this regard (Rezgui and Zarli, 2006). The state of ICTs in the construction industry has drawn the attention of the researchers even in developing countries in which the ICTs utilisation is not as mature as the developed countries (Sarshar and Isikdag, 2004, Ahuja et al., 2009). The case of the future of ICTs in construction looks to be a compromise between accepting something which seems inevitable in some aspects, and an ideal perspective to achieve, since ICTs are able to permeate everything and that the progress in any area could not develop without it (Flangan and Jewell, 2003). On the other hand, some researchers believe that the trend of adopting ICTs within the construction industry should not be an incremental change within the existing paradigm, but it must be a revolutionary movement towards ICT enhancement in 
the industry under question. They argued that the political, structural, and the current barriers will not be effective for keeping away the construction industry from ICTs any more (Brandon et al., 2008). Introducing such a big change within the industry takes a strong motivation. Therefore, the first step towards the enhancement of ICTs implementation in construction relies on the strengthening of the mentioned motivation. This paper aims to present some of the successful strategies in using ICTs and their unique capabilities that can assist the construction industry to enhance various stages of construction operations. Gathering successful cases of ICTs implementation from the fragmented structure of the construction industry along with presenting the advantages will prove useful. This can provide good models for practitioners within the industry. It would be specifically applicable to the policy makers of the projects in developing countries by offering the lessons learned in developed countries with more advances in ICTs.

\section{Definitions}

El-Ghandour and Al-Hussein (2004) consider Information communication technology (ICT) as a collective reference to the integration of computing technology and information processing. ICT in this paper is not a label for reference to a single technology, but it includes a wide range of technical approaches to a variety of problems. Construction processes, in this study, represents the whole life cycle of a construction project, including predesign, design, construction, and operation and maintenance. As the result, in the current paper, ICT can be defined as the application of decision support tools, which uses electronic machines and programs for processing, storage, analysis, control, transfer and presentation of construction information data during the whole life cycle of a construction project.

\section{Methodology}

The approach followed for the purpose of research could be titled as an exhaustive literature review (Cooper, 1988, Randolph, 2009) . It should be mentioned that the literature review provided is based on the focus approach in alignment with the taxonomy of literature reviews by Cooper (1988). Hence, our literature review will focus on outcomes of the previous researches and studies and will not comment on the methodologies of the researches reviewed.

It is noteworthy to say that the models introduced in this paper are the ones picked out as the common place methods mentioned in seminal works from a large number of available methods and strategies in the relevant literature.

\section{Construction Industry Drivers for Adopting ICT}

It seems wrong to regard the driving forces behind the merging of ICTs into construction as isolated factors such as market pull or technology push. What the future holds for the relationship between construction industry and ICTs is shaped by many factors, which have roots in the idiosyncrasies of the construction industry intertwined with the capabilities and the speed of the ICTs as well. Most of the drivers for implementing new technologies and ICTs in construction sector might be similar to those of other industries. In this regard, Table 1 illustrates the main driving forces pushing the adoption of ICT related methods into the construction industry gleaned from existing literature. 
Table1: The driving forces behind the implementation of ICTs within construction industry

\begin{tabular}{|c|c|c|}
\hline Driving force & Brief description & References \\
\hline Productivity & $\begin{array}{l}\text { Increasing the level of productivity in } \\
\text { construction processes }\end{array}$ & $\begin{array}{c}\text { (Ruddock, 2006) } \\
\text { (Milana and Zeli, 2002) } \\
\text { (Kang et al., 2008) }\end{array}$ \\
\hline Globalisation & $\begin{array}{c}\text { The necessity of overcoming the fierce } \\
\text { competition due to the pervasive } \\
\text { globalisation trend }\end{array}$ & $\begin{array}{l}\text { (Duarte and Snyder, } \\
\text { 2006) } \\
\text { (Rezgui and Zarli, 2006) }\end{array}$ \\
\hline \multirow{9}{*}{$\begin{array}{l}\text { Idiosyncrasies of } \\
\text { construction } \\
\text { industry }\end{array}$} & Tight Scheduling necessity & $\begin{array}{l}\text { (Chen and Messner, } \\
\text { 2010) }\end{array}$ \\
\hline & $\begin{array}{l}\text { High dependency on Information and } \\
\text { communication }\end{array}$ & $\begin{array}{l}\text { (Ahuja et al., 2009) } \\
\text { (Huang et al., 2002, } \\
\text { Huang et al., 2007) }\end{array}$ \\
\hline & Being Comprised of SMEs & $\begin{array}{l}\text { (Rezgui and Zarli, 2006) } \\
\text { (Zarli et al., 2004) }\end{array}$ \\
\hline & $\begin{array}{l}\text { Geographical and organisational } \\
\text { proximity issues }\end{array}$ & $\begin{array}{l}\text { (Peansupap and Derek, } \\
\text { 2006) } \\
\text { (Vachara and Derek, } \\
\text { 2005) } \\
\text { (Rezgui and Zarli, 2006) }\end{array}$ \\
\hline & Project orientation of the industry & $\begin{array}{l}\text { (Gann, 1996, Gann and } \\
\text { Salter, 1998, Peansupap } \\
\text { and Derek, 2006) } \\
\text { (Rezgui and Zarli, 2006) }\end{array}$ \\
\hline & Multi-organisational structure & (Love et al., 2004) \\
\hline & Visualisation necessity & $\begin{array}{l}\text { (Brandon et al., 2008) } \\
\text { (Sarshar et al., 2002, } \\
\text { Sarshar and Isikdag, } \\
\text { 2004) }\end{array}$ \\
\hline & $\begin{array}{c}\text { Necessity to gather multi-disciplinary } \\
\text { skills }\end{array}$ & $\begin{array}{l}\text { (Vorakulpipat et al., } \\
\text { 2010) } \\
\text { (Zhang et al., 2007) }\end{array}$ \\
\hline & $\begin{array}{c}\text { Temporary and often short-term nature } \\
\text { of business relationships }\end{array}$ & (Rezgui and Zarli, 2006) \\
\hline
\end{tabular}

Hosseini, M.R., Chileshe, N., Zuo, J. and Baroudi, B. (2012) 'Approaches for implementing ICT technologies within construction industry', Australasian Journal of Construction Economics and Building, Conference Series, 1 (2) 1-12 


\section{Advantages of Utilising ICTs in the Construction Industry}

Discussion about the advantages of implementing any new method including ICTs within the construction industry should be built on the role it might play in facilitating the industry towards meeting its goals successfully. The indices of success in construction projects still suffer from disagreement and ambiguity (Kivrak et al., 2010, Hyvari, 2006, Soon Han et al., 2011). Nevertheless, from some seminal works (Kerzner, 2009) we believe any method improving the performance of construction processes in terms of cost, time, quality and client satisfaction simultaneously could be regarded as advantageous for construction projects. In this regard, the ability of ICTs in improving the completion time of tasks and operations, enhancing collaboration level, facilitating accessibility and exchange of information has been proved in other industries (Stewart and Mohamed, 2003). The use of ICTs improves coordination processes and collaboration between firms participating in a construction project (Nitithamyong and Skibniewski, 2004). One can find many studies confirming the positive impact of utilising ICTs in construction industry with an improving effect on costs, scheduling and quality of construction projects in developed countries (Griffis et al., 1995, Thomas et al., 2001, Yang, 2004). On the other hand, improving the information exchange and communications in projects by adopting ICTs in construction projects has been confirmed by other studies (Adriaanse et al., 2010). Although, some of the studies in developed countries state the positive effect of ICTs on the performance of construction firms as well as on the projects level (Kang et al., 2008), but some of them debate the positive impact of ICTs utilisation on customer satisfaction (El-Mashaleh et al., 2006). The success stories of utilising ICTs in developed countries have drawn the attention of researchers in developing countries regarding the beneficial effects of diffusion of ICTs into construction processes. In this regard, Kivrak et al. (2010) in Turkey confirmed that ICTs implementation has a positive impact on all aspects related to project success criteria including time, cost, competiveness enhancement, and easier information exchange.

The existing literature has a consensus regarding the positive effects of utilising ICTs in construction projects (Adriaanse et al., 2010). However, the same literature holds the view that the level construction industry has harnessed the potential capabilities of ICTs for its own benefit is not as effective as it can be (Hjelt and Björk, 2006, Nitithamyong and Skibniewski, 2004). In this respect, Peansupap (2012) opines that the benefits of ICTs in the construction industry in both the operational and strategic level are not debatable and further research should aim at finding the methods of implementing ICTs methods into the construction industry.

\section{Construction Industry ICT Development Programs}

Many governmental organisations have endeavoured to develop a roadmap for the specific purpose of research and development of ICTs for the construction industry. To gain a better appreciation of the trend, the following works are amongst some of the main construction industry's ICTs development programs.

ROADCON is an accompanying measure (Action Line IST 2002 II.1.2: Strategic roadmaps for applied research) funded by the European Commission under the IST program (Information Society Technologies). Its aim is to develop a roadmap for the research and development of ICT for the construction industry, in the short, medium, and long term. It is promoting model-based, knowledge-driven ICT in the construction sector as the main enabler for the realisation of important societal, environmental, industrial, and business priorities (Rezgui and Zarli, 2006).

ELSEWISE was an EU funded research project. ELSEWISE is a user reference project directed at understanding the information flows within the industry. It then defined the Information Technology and Product Data Technology needs of the European large-scale engineering industry. The ELSEWISE project was a pilot study, which focused on industry

Hosseini, M.R., Chileshe, N., Zuo, J. and Baroudi, B. (2012) 'Approaches for implementing ICT technologies within construction industry', Australasian Journal of Construction Economics and Building, Conference Series, 1 (2) 1-12 
requirements and had a bias towards building and civil engineering construction (Sarshar and Isikdag, 2004).

Information Technology in Construction - Making IT Happen (NSW Government Discussion Paper, 1998) proposed the NSW Government (Australia) strategy to improve construction processes with information technology. This strategy aimed to improve productivity, thereby, reducing cost and time of the capital works procurement process. It also aimed to improve the delivery of a building or facility, meeting clients' needs. The role of ICT in the future of the construction industry was discussed, and a three-step approach was proposed for bringing about a rational adoption by the industry of information technology. Defining a Research Agenda for AEC Process/Product Development in 2000 was a workshop held by BerkeleyStanford in 1999. It aimed at defining a research agenda for AEC Process/Product Development in 2000 and beyond. The proceedings of this workshop have been examined to find out new trends of construction ICT in the world. Over 150 papers were presented (Sarshar and Isikdag, 2004).

"Think Lab" is an state-of-the-art facility established by the University of Salford for the purpose of research into information and communication technologies in many fields, including design and construction. It provides a forum for leading figures across the world to participate, both in person and through virtual collaborative technologies, to discuss topics relating to future developments in ICTs application to design and construction areas (Brandon et al., 2008).

The Australian Cooperative Research Centre (CRC) for construction innovation formed in 2001 is committed to leading the Australian construction industry in collaboration and innovation. They prepared the report "Construction 2020" to determine the main trend that Australian construction industry should follow and the relevant barriers and initiatives. It started by holding a series of workshops in 2003 and 2004 in every capital city of Australia for seeking the views of industry leaders into the future of construction industry in Australia extended to the year 2020. The report committee considered all the conditions of the global, local market along with the current state of the industry under question. Integration of computer technologies and knowledge sharing methods were found to be the second perceived priority of the respondents of the research (Hampson and Brandon, 2004).

CII or the Construction Industry Institute embarked on a study focusing on making virtual teams work in the engineering, procurement, and construction (EPC) industry. The scope of this effort included the examination of current research on the topic, a study of current virtual team practices within the industry, the study of cases outside the EPC industry, and the development of recommendations for successfully implementing virtual teams in the EPC industry. This paper presents the critical findings from this research effort, emphasising the managerial and technological guidelines developed to successfully implement virtual teams in the construction and engineering industries (Chinowsky et al., 2002).

A large amount of literature regarding the necessity of construction merging into ICTs exists with some of thoughts mentioned above. It seems there is widespread consensus among the practitioners, people in the industry, executives, and scholars about the necessity of augmenting the utilisation of ICTs within construction industry by all possible means. Having synthesised the construction industry needs and requirements in relation to the adoption and use of ICTs, the question remains to be answered: "How and in which systematic models ICTs might benefit the construction industry of the future?"

This question has been the focus of many studies and scientific reports in the past decade. Generally, the underpinning idea in future use of ICTs is computer-interpretable information. This phenomenon could be adopted in different models to enable enhanced automation, integration, and communication in construction industry (Rezgui and Zarli, 2006). The following literature describes some samples of systematic utilisation of ICTs in construction 
industry and some of the successfully experienced models applied in the past. As we stated before, the approaches presented, include solely some of the previously experienced methods of utilising ICTs to enhance aspects within the construction industry. Determining all the possible ways of merging ICTs into construction requires comprehensive research and is beyond the scope of this paper.

\section{Different Methods of Implementing ICTs within the Construction Industry}

\section{Virtual construction before starting the procurement}

One of the most significant aspirations in construction in recent years has been the desire to build a building in a virtual environment before commencing the process of the construction and even before starting the procurement process, thus enabling the constructability of a project to be tested. This came to fruition in the 2006 and 2007 with researchers developing visual simulations of the construction process, working with CATIA. This method has enabled significant savings to be made by contractors and enabled design solutions to be tested for their viability and efficiency. This has been regarded as a major step forward and challenges the existing methods of evaluation that are often locked into historical precedent which is no longer applicable (Li et al., 2009b, Li et al., 2009a, Li et al., 2008, Brandon et al., 2008).

\section{Virtual prototyping (VP)}

Virtual prototyping is the exploitation of simulation process for the test, evaluation and modification of prototypes in virtual design environment with the intention of obviating the need for physical models. Virtual prototyping typically involves analysing CAD models for different end user applications, such as manufacturability and applying these results to latter phases. VP exploits simulation process for the testing, evaluation, and modification of design prototypes from conceptual design to the final product. In the construction design phase, it will help the designers visualise the interactive results of design modifications, allow tests to be performed during each phase of product development, help programme managers identify programme risks, enhance economic competiveness, etc. (Brandon et al., 2008).

Rapid prototyping or RP is the production of a physical model from a computer model. In the last years, a couple of RP techniques have come to existence for enhancing the design process. Prototyping technologies have different suitability and effectiveness for various stages of the design cycle with respect to their relevance in design and manufacture (Sass, 2008, Sass and Oxman, 2006, Villalon and Lobel, 2007).

\section{nD modelling}

A building information model (BIM) is a computer database of building design information, which may also contain information about the building's construction, management, operations and maintenance. An $\mathrm{nD}$ model is an extension of the BIM, incorporating all the design information required at each stage of the life cycle of the construction project. From this database, different views of the information can be generated automatically, views that correspond to traditional design documents such as plans, sections, elevations, and schedules. As the documents are derived from the same database, they are all coordinated and accurate. Any design changes in the model will be reflected automatically in the resulting drawings, ensuring a complete and consistent set of documentation. nD builds upon the concept of 2D, 3D and 4D.

3D modelling in construction goes beyond the object's geometric dimensions and replicates visual attributes such as colour or texture. This visualisation is the common attribute of any design packages, which enable the simulation of reality in all its aspects or allow rehearsal 
medium for strategic planning. Combining the time sequence in visual environments with the $3 \mathrm{D}$ geometric model is commonly referred to as $4 \mathrm{D}$. By utilising $4 \mathrm{D}$ the procedure of construction could be demonstrated before any real construction activity has been commenced. It helps the stakeholders to define any possible faults or mistakes at the early stages of the project. It also enables them to predict the project's schedule. This method has received acceptance from the practitioners in the field. Utilising 4D modelling has been used in many projects such as Walt Disney Concert Hall Project, University of Teeside's Vircon project, etc.

$\mathrm{nD}$ modelling builds on the concept of $4 \mathrm{D}$ modelling by integrating an nth number of design dimensions into a more holistic model which would enable users to portray and visually project the construction design over its complete life cycle (Brandon et al., 2008).

\section{Global Engineering Networks (GEN)}

Companies increasingly disperse their engineering operations to support global business, to access global resources, or to achieve global efficiency. In addition to the increasing dispersion and engineering management has to cope with increasing changes and uncertainties, global competition and the ever-changing markets and technologies. Hence, evolving with the environment the method of managing operations should be changed fundamentally (Zhang et al., 2007).

To address the abovementioned issue, researchers have proposed integrating frameworks to present the essential elements of global engineering networks (GENs) from the perspectives of the context, capability, and configuration (3C). Using the 3C framework, three key patterns (efficient GEN, flexible GEN, and innovative GEN) of the leading practice had been identified in these researches (Zhang et al., 2007, Zhang et al., 2008, Karandikar and Nidamarthi, 2006, Shott and Birkhofer, 1996).

Essential characteristics of effective engineering networks include:

(a) Global engineering operations - managing globally dispersed resources to obtain the dual benefits of global integration and local responsiveness;

(b) Engineering knowledge management - managing both explicit and tacit knowledge to improve global engineering performance in dynamic and unpredictable business environments;

(c) Networked resources - using the capabilities, configurations, and behaviours of networks to create a new approach to engineering management building on the success of existing processes and practices

(d) Information technologies (IT) enabled and integrated- using IT tools, processes, and infrastructures to integrate the key characteristics of the network approach (Zhang et al., 2006).

To sum up, the GEN framework can direct companies to search for best practices across the company or industries, and can offer companies a more holistic view when transferring the proper best practice. Companies need to perform this procedure and improve their engineering networks regularly. Continuous improvement moves engineering networks towards perfection (Zhang et al., 2007, Zhang et al., 2008).

\section{Collaborative virtual teams}

All the mentioned methods are just some specific methods introduced to the construction industry having been built upon the capabilities of ICT. But to be more precise, based on the literature review it is suggestible that one of the most advantageous possible approaches to adopting ICT into construction industry would be to enhance the communication 
management and the transfer of information amongst different organisations, different stakeholders, different actors in the project, different teams, and even among the team members inside an organisation (Kivrak et al., 2010, Koskela and Kazi, 2003, Love et al., 2004, Peansupap and Walker, 2005, Peansupap and Walker, 2006, Sarshar et al., 2002, Soliman and Janz, 2004, Zarli et al., 2004, Bresnen and Marshall, 2001, Peansupap and Derek, 2006, Ahuja et al., 2009, Adriaanse et al., 2010).

One of the commonplace measures recommended by the reports and research papers is to develop collaborative virtuality within the processes of construction industry (Rezgui and Zarli, 2006, Chinowsky et al., 2002), which has been selected as the main focus of this research. Therefore, the following sections of this research are allocated to describe the phenomenon of virtual teams within the construction industry. Virtual teams heavily rely on ICT related technologies to foster their operations (Yacine, 2007), and the construction industry has been always some distance behind business and manufacturing in taking up ICT (Brandon et al., 2008).

\section{Discussion}

Although the positive effects of ICT implementation in construction processes have been seen in numerous previous experiences and projects, it takes investment, which necessitates intensive support from the managerial levels of construction companies (Peansupap and Derek, 2006). In addition, the cultural issues related to the apathy of employees for utilising ICTs and their learning related issues should be taken into account (Koskela and Kazi, 2003). The authors believe that the appropriate technology is now available for serving the construction industry effectively. Only the barriers such as the matters mentioned above hinder the migration of construction industry for harnessing the capabilities of ICTs. The major obstacle seems to be the lack of appreciation of managers regarding the new available technologies and the benefits they would bring about for the construction organisations. Managers should conclude that spending on ICTs in their projects and organisations is not expenditure, but it is an investment with long term positive effects in terms of enhancing the productivity of human resources within their organisations. Hence, in alignment with discussions presented by Sutton and Lemay (1999) and Whyte et al., (2002) the view is held that construction practitioners should take advantage of effective strategies for enhancing the culture of ICTs implementation in construction projects. As an example, the obstacles due to lack of support from managers would be resolved by adopting small low budget pilot projects to utilise ICTs in construction projects and prove the benefits to different levels of the organisation. Scholars also have a duty of collecting data on successful projects that use ICTs with the aim of sharing the information with all sectors of the industry.

\section{Conclusions}

This paper introduced some of the methods of merging ICTs into different phases and processes of construction projects. Based on the literature review some institutions and organisations are acting to expedite the ICTs implementation procedure. ICTs technologies are mature enough for alleviating the current issues rampant on construction projects and the successful methods to utilise them have been implemented on some projects. Hence, although not perfect, the true potential for positive impacts from ICTs on construction processes exists now.

The sizeable proportions of literature available advocate the fact that the main barriers hindering the migration of construction industry towards further utilisation of ICT come from cultural grounds. Authors are of the view that the next challenging task ahead of construction practitioners and researchers would be to foster the culture of utilising ICTs in the different

Hosseini, M.R., Chileshe, N., Zuo, J. and Baroudi, B. (2012) 'Approaches for implementing ICT technologies within construction industry', Australasian Journal of Construction Economics and Building, Conference Series, 1 (2) 1-12 
phases of the construction industry. Future researchers will contribute to the construction industry if they aim to determine the factors affecting the ICT utilisation culture on construction projects in developed and developing countries. Enhancing the positive factors and eliminating variables with an adverse effect on ICT utilisation within the construction industry can provide for good outcomes. After ascertaining all the influential factors, further research could be concentrated on defining the most effective strategies or methods to foster the migration of construction practitioners from conventional methods to ICT based approaches. Further investigations should presents frameworks for facilitating managing change in construction companies that want to adopt ICT as a dominant element for delivering project efficiently. We would argues that a deep appreciation of the dynamics of change at the people/technology interaction, along with in-detail awareness of the benefits of adopting ICT, is a prerequisite for the successful implementation of advantageous ICT based approaches in construction projects. As distinctive suggestions, the authors propose improving the procedures of merging ICT into construction processes taking into account the cognitive systems engineering (CSE) principles as a fertile ground for future researchers.

\section{References}

Adriaanse, A., Voordijk, H. \& Dewulf, G. 2010. The Use Of Interorganisational ICT In United States Construction Projects. Automation In Construction, 19, 73-83.

Ahuja, V., Yang, J. \& Shankar, R. 2009. Study Of ICT Adoption For Building Project Management In The Indian Construction Industry. Automation In Construction, 18, 415-423.

Andresen, J., Björk, B. \& Betts, M. 2000. A Framework For Measuring It Innovation Benefits.

Brandon, P. S., Kocaturk, T. \& Foundation, R. 2008. Virtual Futures For Design, Construction \& Procurement, Malden, Ma, Blackwell Pub.

Bresnen, M. \& Marshall, N. 2001. Understanding The Diffusion And Application Of New Management Ideas In Construction. Engineering Construction And Architectural Management, 8, 335-345.

Chee, H. W. 2007. ICT Implementation And Evolution. Construction Innovation, 7, 254-273.

Chen, C. \& Messner, J. I. 2010. A Recommended Practices System For A Global Virtual Engineering Team. Architectural Engineering And Design Management, 6, 207-221.

Chinowsky, P. S., Rojas, E. \& Team, U. O. T. A. A. C. I. I. M. V. T. W. P. 2002. Virtual Teams: A Guide To Successful Implementation ; A Report To Construction Industry Institute, The University Of Texas At Austin, Construction Industry Institute.

Cooper, H. M. 1988. Organizing Knowledge Syntheses: A Taxonomy Of Literature Reviews. Knowledge, Technology \& Policy, 1, 104-126.

Davis, K. \& Songer, A. D. 2008. Resistance To It Change In The AEC Industry: An Individual Assessment Tool. Construction Management Faculty Publications And Presentations, 1.

Duarte, D. L. \& Snyder, N. T. 2006. Mastering Virtual Teams: Strategies, Tools, And Techniques That Succeed, Jossey-Bass Inc Pub.

El-Ghandour, W. \& Al-Hussein, M. 2004. Survey Of Information Technology Applications In Construction. Construction Innovation: Information, Process, Management, 4, 83-98.

El-Mashaleh, M., O'brien, W. J. \& Minchin Jr, R. E. 2006. Firm Performance And Information Technology Utilization In The Construction Industry. Journal Of Construction Engineering And Management, 132, 499.

Flangan, R. \& Jewell, C. 2003. A Review Of Recent Work On Construction Future. Crisp Commission, 02/06.

Gajendran, T. \& Brewer, G. 2012. Cultural Consciousness And The Effective Implementation Of Information And Communication Technology. Construction Innovation: Information, Process, Management, 12, 179-197.

Hosseini, M.R., Chileshe, N., Zuo, J. and Baroudi, B. (2012) 'Approaches for implementing ICT technologies within construction industry', Australasian Journal of Construction Economics and Building, Conference Series, 1 (2) 1-12 
Gann, D. M. 1996. Construction As A Manufacturing Process? Similarities And Differences Between Industrialized Housing And Car Production In Japan. Construction Management \& Economics, 14, 437-450.

Gann, D. M. \& Salter, A. 1998. Learning And Innovation Management In Project-Based, ServiceEnhanced Firms. International Journal Of Innovation Management, 2, 431-454.

Griffis, F. H., Hogan, D. B. \& Li, W. 1995. An Analysis Of The Impact Of Using Three Dimensional Computer Models In The Management Of Construction. Construction Industry Institute (Cii) Austin, Tx, Usa, Research Report 106-11.

Hampson, K. D. \& Brandon, P. 2004. Construction 2020-A Vision For Australia's Property And Construction Industry, Crc Construction Innovation.

Hannus, M., Blasco, M., Bourdeau, M., Böhms, M., Cooper, G., Garas, F., Hassan, T., Kazi, A., Leinonen, J. \& Rezgui, Y. 2003. Construction Ict Roadmap. Roadcon Project Deliverable Report D, 52.

Hjelt, M. \& Björk, B. C. 2006. Experiences Of Edm Usage In Construction Projects. Journal Of Information Technology In Construction, 11, 113-125.

Huang, C., Fisher, N. \& Broyd, T. Development Of A Triangular Tpc Model To Support Adoption Of Construction Integrated System. 2002. 427-438.

Huang, T., Kong, C. W., Guo, H. L., Baldwin, A. \& Li, H. 2007. A Virtual Prototyping System For Simulating Construction Processes. Automation In Construction, 16, 576-585.

Hyvari, I. 2006. Success Of Projects In Different Organizational Conditions. Project Management Journal, 37, 31.

Kang, Y., O'brien, W. J., Thomas, S. \& Chapman, R. E. 2008. Impact Of Information Technologies On Performance: Cross Study Comparison. Journal Of Construction Engineering \& Management, 134, 852-863.

Karandikar, H. \& Nidamarthi, S. 2006. A Model For Managing The Transition To A Global Engineering Network Spanning Industrialized And Emerging Economies. Journal Of Manufacturing Technology Management, 17, 1042-1057.

Kerzner, H. 2009. Project Management: A Systems Approach To Planning, Scheduling, And Controlling, Wiley.

Kivrak, S., Arslan, G. \& Cagatay, O. 2010. Information Technology Usage Impacts On Construction Projects'success.

Koskela, L. \& Kazi, A. S. 2003. Information Technology In Construction: How To Realise The Benefits? Socio-Technical And Human Cognition Elements Of Information Systems, 60-75.

Li, H., Chan, N., Huang, T., Guo, H. L., Lu, W. \& Skitmore, M. 2009a. Optimizing Construction Planning Schedules By Virtual Prototyping Enabled Resource Analysis. Automation In Construction, 18, 912-918.

Li, H., Huang, T., Kong, C. W., Guo, H. L., Baldwin, A., Chan, N. \& Wong, J. 2008. Integrating Design And Construction Through Virtual Prototyping. Automation In Construction, 17, 915-922.

Li, H., Lu, W. \& Huang, T. 2009b. Rethinking Project Management And Exploring Virtual Design And Construction As A Potential Solution. Construction Management And Economics, 27, 363-371.

Love, P. E. D., Irani, Z. \& Edwards, D. J. 2004. Industry-Centric Benchmarking Of Information Technology Benefits, Costs And Risks For Small-To-Medium Sized Enterprises In Construction. Automation In Construction, 13, 507-524.

Love, P. E. D., Irani, Z., Li, H., Cheng, E. W. L. \& Raymond, Y. 2001. An Empirical Analysis Of The Barriers To Implementing E-Commerce In Small-Medium Sized Construction Contractors In The State Of Victoria, Australia. Construction Innovation: Information, Process, Management, 1, 31-41.

Milana, C. \& Zeli, A. 2002. The Contribution Of Ict To Production Efficiency In Italy: Firm-Level Evidence Using Data Envelopment Analysis And Econometric Estimations. Oecd Publishing.

Hosseini, M.R., Chileshe, N., Zuo, J. and Baroudi, B. (2012) 'Approaches for implementing ICT technologies within construction industry', Australasian Journal of Construction Economics and Building, Conference Series, 1 (2) 1-12 
Nitithamyong, P. \& Skibniewski, M. J. 2004. Web-Based Construction Project Management Systems: How To Make Them Successful? Automation In Construction, 13, 491-506.

Peansupap, V. 2012. An Exploratory Approach To The Diffusion Of Ict In A Project Environment.

Peansupap, V. \& Derek, H. T. W. 2006. Information Communication Technology (Ict) Implementation Constraints. Engineering, Construction And Architectural Management, 13, 364-379.

Peansupap, V. \& Walker, D. 2005. Exploratory Factors Influencing Information And Communication Technology Diffusion And Adoption Within Australian Construction Organizations: A Micro Analysis. Construction Innovation: Information, Process, Management, 5, 135-157.

Peansupap, V. \& Walker, D. H. T. 2006. Information Communication Technology (Ict) Implementation Constraints: A Construction Industry Perspective. Engineering, Construction And Architectural Management, 13, 364-379.

Randolph, J. J. 2009. A Guide To Writing The Dissertation Literature Review. Practical Assessment, Research \& Evaluation, 14, 2.

Rezgui, Y. \& Zarli, A. 2006. Paving The Way To The Vision Of Digital Construction: A Strategic Roadmap. Journal Of Construction Engineering And Management, 132, 767.

Ruddock, L. 2006. Ict In The Construction Sector: Computing The Economic Benefits. International Journal Of Strategic Property Management, 10, 39-50.

Sarshar, M. \& Isikdag, U. 2004. A Survey Of Ict Use In The Turkish Construction Industry. Engineering, Construction And Architectural Management, 11, 238-247.

Sarshar, M., Tanyer, A. M., Aouad, G. \& Underwood, J. 2002. A Vision For Construction It 20052010: Two Case Studies. Engineering Construction And Architectural Management, 9, 152-160.

Sass, L. 2008. A Production System For Design And Construction With Digital Fabrication.

Sass, L. \& Oxman, R. 2006. Materializing Design: The Implications Of Rapid Prototyping In Digital Design. Design Studies, 27, 325-355.

Shott, H. \& Birkhofer, H. Global Engineering Network-Applications For Green Design. 1996. 93-105.

Soliman, K. S. \& Janz, B. D. 2004. An Exploratory Study To Identify The Critical Factors Affecting The Decision To Establish Internet-Based Interorganizational Information Systems. Information \& Management, 41, 697-706.

Soon Han, W., Md Yusof, A., Ismail, S. \& Choon Aun, N. 2011. Reviewing The Notions Of Construction Project Success. International Journal Of Business And Management, 7, P90.

Stewart, R. A. \& Mohamed, S. 2003. Evaluating The Value It Adds To The Process Of Project Information Management In Construction. Automation In Construction, 12, 407-417.

Sutton, M. J. D. \& Lemay, P. J. 1999. Terms Of Reference: The Foundation For Implementing Document Management Systems. Information Systems Management, 16, 78-83.

Thomas, S. R., Macken, C. L. \& Lee, S. H. 2001. Impacts Of Design/Information Technology On Building And Industrial Projects. A Report Submitted To Nist, Construction Industry Institute, University Of Texas, Austin, Tx.

Vachara, P. \& Derek, W. 2005. Factors Affecting Ict Diffusion. Engineering, Construction And Architectural Management, 12, 21-37.

Villalon, R. \& Lobel, J. 2007. Materializing Design: Contemporary Issues In The Use Of Cad/Cam Technology In The Architectural Design And Fabrication Process. Proc. Ascaad 2007.

Vorakulpipat, C., Rezgui, Y. \& Hopfe, C. J. 2010. Value Creating Construction Virtual Teams: A Case Study In The Construction Sector. Automation In Construction, 19, 142-147.

Whyte, J., Bouchlaghem, D. \& Thorpe, T. 2002. It Implementation In The Construction Organization. Engineering Construction And Architectural Management, 9, 371-377.

Yacine, R. 2007. Exploring Virtual Team-Working Effectiveness In The Construction Sector. Interacting With Computers, 19, 96-112.

Hosseini, M.R., Chileshe, N., Zuo, J. and Baroudi, B. (2012) 'Approaches for implementing ICT technologies within construction industry', Australasian Journal of Construction Economics and Building, Conference Series, 1 (2) 1-12 
Yang, L. R. 2004. Project Performance Versus Use Of Technologies At Project And Phase Levels. Journal Of Construction Engineering And Management, 130, 322.

Zarli, A., Rezgui, Y. \& Kazi, A. S. S. Present And Future Of European Research On Information Technologies In Construction. 2004. Asce.

Zhang, Y., Gregory, M. \& Shi, Y. Foundations Of Global Engineering Networks: Essential Characteristics Of Effective Engineering Networks. 2006. leee, 1113-1117.

Zhang, Y., Gregory, M. \& Shi, Y. 2007. Global Engineering Networks: The Integrating Framework And Key Patterns. Proceedings Of The Institution Of Mechanical Engineers, Part B: Journal Of Engineering Manufacture, 221, 1269-1283.

Zhang, Y., Gregory, M. \& Shi, Y. 2008. Global Engineering Networks (Gen): Drivers, Evolution, Configuration, Performance And Key Patterns. Journal Of Manufacturing Technology Management, 19, 299-314. 